\title{
ARTICLE OPEN \\ Implication of 5-HT7 receptor in prefrontal circuit assembly and detrimental emotional effects of SSRIs during development
}

\author{
Jimmy Olusakin ${ }^{1,2,8}$, Imane Moutkine $^{1,2}$, Sylvie Dumas ${ }^{3}{ }^{3}$, Evgeni Ponimaskin ${ }^{4}$, Eleni Paizanis ${ }^{5}$, Mariano Soiza-Reilly (iD ${ }^{1,2,6}$ and \\ Patricia Gaspar (iD ${ }^{1,2,7}$
}

\begin{abstract}
Altered development of prefrontal cortex (PFC) circuits can have long-term consequences on adult emotional behavior. Changes in serotonin homeostasis during critical periods produced by genetic or pharmacological inactivation of the serotonin transporter (SERT, or Slc6a4), have been involved in such developmental effects. In mice, selective serotonin reuptake inhibitors (SSRIs), administered during postnatal development cause exuberant synaptic connectivity of the PFC to brainstem dorsal raphe nucleus (DRN) circuits, and increase adult risk for developing anxiety and depressive symptoms. SERT is transiently expressed in the glutamate neurons of the mouse PFC, that project to the DRN. Here, we find that 5-HTR7 is transiently co-expressed with SERT by PFC neurons, and it plays a key role in the maturation of PFC-to-DRN synaptic circuits during early postnatal life. 5-HTR7-KO mice show reduced PFC-to-DRN synaptic density (as measured by array-tomography and VGLUT1/synapsin immunocytochemistry). Conversely, 5-HTR7 over-expression in the developing PFC increased PFC-to-DRN synaptic density. Long-term consequences on depressive-like and anxiogenic behaviors were observed in adults. 5-HTR7 over-expression in the developing PFC, results in depressive-like symptoms in adulthood. Importantly, the long-term depressive-like and anxiogenic effects of SSRIs (postnatal administration of fluoxetine from P2 to P14) were not observed in 5-HTR7-KO mice, and were prevented by co-administration of the selective inhibitor of 5-HTR7, SB269970. This study identifies a new role 5-HTR7 in the postnatal maturation of prefrontal descending circuits. Furthermore, it shows that 5-HTR7 in the PFC is crucially required for the detrimental emotional effects caused by SSRI exposure during early postnatal life.
\end{abstract}

Neuropsychopharmacology (2020) 45:2267-2277; https://doi.org/10.1038/s41386-020-0775-z

\section{INTRODUCTION}

Enhanced vulnerability to emotional disorders such as anxiety and depression can result from altered developmental trajectories during early life [1]. This, in turn, can be related to a combination of genetic and environmental factors including early-life stress, malnutrition, or drug exposure. In these conditions, perturbed serotonin (5-HT) signaling has been implicated as a causal agent because of its impact on brain development [2-4].

One of the most remarkable and clinically relevant examples of 5 -HT's developmental effects is the exposure of human fetuses or infants to selective serotonin reuptake inhibitors (SSRIs) [5]. Contrasting with their antidepressant effects in adulthood, fluoxetine, as other SSRIs, when administered during early life, have long-term effects on adult emotional behavior including enhanced anxiety and depressive-like phenotypes [6]. Similarly, serotonin transporter (SERT) knock-out mice show increased anxiety and depressive-like behaviors [7, 8], and humans carrying the hypofunctional s-allele of the SERT gene have increased risk to mood disorders after early adversity [9, 10]. Overall, these observations indicated that increased $5-\mathrm{HT}$ signaling obliterates normal physiological balances during a critical period when the neural circuits that underlie stress-related behaviors are being remodeled by activity-dependent processes [11].

The difference in the action of SSRIs in development and adults could be explained by changes in cellular targets of SSRIs at different critical periods of life. While SERT is expressed exclusively in the 5-HT-producing neurons of the raphe nuclei in adult brain, it has a broader expression during fetal and early postnatal life in rodents $[12,13]$ and primates including humans $[[14,15]$; http://www.brainspan.org]. This suggested that SERT has specific developmental functions, in particular to buffer 5-HT accumulation and thereby controlling 5-HT receptor (5-HTR) activation $[3,16]$. Recently, a key neuronal circuit involved in mood control, the descending prefrontal projection to raphe neurons [17-19] has been found to transiently express SERT, during the first 2 weeks of life. SERT is expressed in layer 5-6 glutamate projection neurons of the prefrontal cortex (PFC), in particular those projecting to the dorsal raphe nucleus (DRN). Genetic ablation or pharmacological blockade of SERT function in these neurons alters the glutamatergic synapse development [20].

\footnotetext{
${ }^{1}$ Institut du Fer à Moulin, INSERM, UMR-S, 1270 Paris, France; ${ }^{2}$ Sorbonne Université, Paris, France; ${ }^{3}$ Oramacell, Paris 75006, France; ${ }^{4}$ Hannover Medical School (MHH), Hannover,

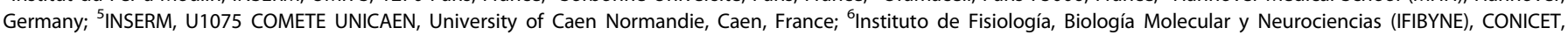
Universidad de Buenos Aires, Buenos Aires, Argentina and ${ }^{7}$ Institut du Cerveau et de la Moëlle, CNRS UMR 7225-Inserm U1127, Paris, France Correspondence: Mariano Soiza-Reilly (msoizareilly@fbmc.fcen.uba.ar) or Patricia Gaspar (patricia.gaspar@inserm.fr)

${ }^{8}$ Present address: Département des Neurosciences Fondamentales, College of Médecine, University of Geneva, 1 rue Michel Servet, 1211 Geneva, Switzerland
}

Received: 19 May 2020 Revised: 6 July 2020 Accepted: 9 July 2020

Published online: 20 July 2020 
We reasoned that 5 -HTRs expressed simultaneously with SERT in the PFC, would be likely candidates to mediate these developmental effects. Based on gene expression profiling we identified the 5-HTR7 as a possible candidate. The 5-HTR7 promotes axon growth and synaptogenesis in vitro [21-23], suggesting a role in neural circuit development and structural plasticity [24]. Moreover, 5-HTR7 has been implicated in mood control, based on pharmacological studies showing that antagonizing 5-HTR7 attenuates anxiety and depression-like phenotypes [25-28]. Furthermore, a variant of 5-HTR7 has been associated to a better response to SSRIs in bipolar patients [29].

In the present study, we used a combination of genetic, pharmacological and high-resolution imaging approaches to evaluate the developmental role of 5-HTR7 in the synaptic wiring of the PFC-to-DRN circuit and adult emotional behavior. We provide converging evidence that 5-HTR7 is crucially required for the detrimental developmental effects of SSRIs on the PFC circuit assembly, with a direct impact on adult emotional control.

\section{METHODS AND MATERIALS}

Animals

Animal care and experiments were conducted in accordance with the institutional guidelines. All procedures have been approved by the ethical committee of the region lle de France (Comité Darwin, agreement 09047.04). C57BL/6 (Janvier, France) and 5-HTR7 knockout $\left(5-\mathrm{HTR}^{-1-}\right)$ mice $[26,30]$, maintained on a $\mathrm{C} 57 \mathrm{BL} / 6$ background, were used. At arrival, pregnant females were grouphoused by 2 and litter sizes were homogenized from 8-14 animals with both sexes represented. After weaning at P21, all mice were group-housed by sex (4-5 per cage), and kept under standard laboratory conditions $\left(22 \pm 1{ }^{\circ} \mathrm{C}, 60 \%\right.$ relative humidity, $12-12 \mathrm{~h}$ light-dark cycle, food and water ad libitum) in ventilated racks. Male and female mice were used, and the number of individuals used are provided in Figure legends.

\section{Drug administration}

Fluoxetine hydrochloride (FLX, Tocris, UK) and SB269970 (Abcam, \#ab120508) were used. FLX was diluted in $3 \%$ sucrose when administered orally, or in saline $(0.9 \% \mathrm{NaCl})$ when administered subcutaneously. Subcutaneous injections $(1 \mathrm{ml} / \mathrm{kg})$ were carried out only in experiments where pups received a second treatment that cannot be orally administered (i.e., SB269970) [31]. SB269970 was administered at $10 \mathrm{mg} / \mathrm{kg}$ twice daily based on previous studies [28].

Mixed litters born from $5-\mathrm{HTR}^{-1-} \times 5-\mathrm{HTR}^{+/-}$breedings were given FLX (10 mg/kg/day) or sucrose ( $3 \%$ in water) orally from P2 to P14. Litters were separated from their dam, weighed, and fed either the FLX/sucrose or sucrose solution with a P10 pipette, before being returned to their dams. As pups very readily absorb the sucrose, the entire procedure lasted $<5$ min per litter, and had no visible consequences on maternal care to pups. Genotyping was performed at weaning using primers to detect the neo cassette and the deleted exon 2 gene (Supplementary Table S1).

Litters of $\mathrm{C} 57 \mathrm{BL} / 6$ mice were randomly assigned to: Saline (Control; 0.9\% NaCl/24 h); Fluoxetine (FLX; $10 \mathrm{mg} / \mathrm{kg} / 24 \mathrm{hs);} \mathrm{FLX}$ ( $10 \mathrm{mg} / \mathrm{kg} / 24 \mathrm{~h}$ ) plus SB269970 (10 mg/kg/12 h) (in this condition, FLX was co-administered with one of the SB269970 injections); and SB269970 (10 mg/kg/12 h). Drugs and vehicle were administered s.c. from $\mathrm{P} 2$ to $\mathrm{P} 14$.

\section{RT-qPCRs}

Brains of mice euthanized at P1, P7, P14, and P60 ( $n=5 /$ age) were extracted and kept on ice while PFCs were dissected out. 2-3 brains were pooled for each age analyzed. Samples were directly processed for RNA isolation with Trizol reagent (ThermoFisher, France, \#15596026) following standard protocols. Genomic DNA was cleared using DNasel (ThermoScientific, France, \#EN0521) and
RT-PCR was done with SuperScript II kit (Invitrogen, USA, \#18064014) using ThermoScientific SYBR Green Mix. Primers are provided in Supplementary Table S1.

In situ hybridization (ISH)

The following probes were used for 5-HTR7 mRNA: NM_008315.3 sequence 602-1372, Slc6a4 mRNA: NM_013034.4 sequence 1192-2047, and GFP: NM_013645 sequence 74-588.

Brains of P0, P7, P14, P21, and adult mice ( $n=3-4$ /age; P0 $=$ birth) were rapidly frozen in isopentane at $-30{ }^{\circ} \mathrm{C}$ and stored at $-80^{\circ} \mathrm{C}$. Tissue blocks were sectioned at $15 \mu \mathrm{m}$ on a cryostat, and dried at $-20^{\circ} \mathrm{C}$ for at least $60 \mathrm{~min}$.

Colorimetric ISH was carried out as described previously [32], using a 5-HTR7 DIG-labeled probe, phosphatase-coupled anti-DIG antibodies (1:1000), and developed with NBT/BCIP. For double labeling experiments the RNAscope Multiplex Fluorescent Reagent Kit (Advanced Cell Diagnostics, France) was used. Probes were designed by Advanced Cell Diagnostics to target: S/c6a4 (\#315851) and 5-HTR7 (\#401321-C3). ISH was performed according to the protocol of the RNAscope Multiplex Fluorescent Reagent Kit v1 (\#320851). Before mounting, sections were incubated with DAPI. ISH imaging was done in a Zeiss Axioscan microscope at 20X, while FISH images were acquired with a confocal microscope at $20 \mathrm{X}$ and $63 \mathrm{X}$.

\section{5-HTR7-EGFP construct}

The construction of the 5-HTR7 fused to EGFP has been described previously [33]. The 5-HTR7-EGFP fusion construct was then cloned into an AAV plasmid under control of the neuron specific synapsin promoter [34]. This plasmid was used for production of the rAAV8 (Vector Core, Univ. North Carolina, USA) coding for 5-HTR7-EGFP. AAV-9-hSyn-eGFP-WPRE-bGH (Penn Vector Core, USA) was used as sham. The AAV8-9 serotypes were chosen based on the rapidity and efficiency of neuronal transfection [35].

\section{PFC viral injections}

Newborn mice were separated from their dams and randomly assigned to 5-HTR7 overexpression group (rAAV8-Syn(H1-2)-5HTR7-EGFP) or sham group (AAV-9-hSyn-EGFP-WPRE-bGH). Titer ranges were of $10^{12}-10^{13}$ particles/ml. P1 pups were coldanesthetized and bilaterally injected $(50 \mathrm{nl}$ each) using a pulled glass capillary mounted on a hydraulic micromanipulator as before [20]. The whole procedure takes about 5-10 min per pup. After surgeries, pups were warmed and rapidly returned to their home cages with the mothers.

\section{Array tomography}

Fixed brain tissue containing the DRN were processed for array tomography as previously $[36,37]$. Tissue was ultrasectioned in series of $25100 \mathrm{~nm}$-thick sections in an ultramicrotome (Leica) $[36,37]$. Polyclonal antibodies anti-Tryptophan hydroxylase (sheep, 1:200; Millipore, USA; AB1541), anti-VGLUT1 (guinea pig, 1:1000; Millipore, USA; AB5905) and anti-Synapsin 1a (rabbit, 1:200; Cell Signaling Technology, MA, USA; D12G5 XP, \#5297S) were used [37]. Fluorescent-conjugated secondary antisera raised in donkey (Alexa 488,647 and CY3, 1:100; Jackson ImmunoResearch, USA) were applied for revelation. Sections were imaged in a Leica DM6000 fluorescence microscope using a 63X NA 1.4 oil objective. Serial images were processed and analyzed using Fiji as described previously [36, 37].

Behavioral studies

Behavioral measurements started at P80 in the following sequence: (1) Open field (OF), (2) Splash test (ST), (3) Noveltysuppressed feeding (NSF), (4) Forced-swim test (FST) and 5) Locomotion. 2-day interval was set between the OF and ST and 7day interval between the NSF, FST and locomotor tests to 
minimize interferences. Behaviors were done during the light cycle (10 a.m.-5 p.m.) as previously $[20,35]$.

Open field

Mice were allowed to explore brightly lit (400-500 lux) chambers $[50 \mathrm{~cm} \times 50 \mathrm{~cm} \times 45 \mathrm{~cm}$ ] equipped with an infrared camera (B/WCCD with CCTV lens $2.8-12 \mathrm{~mm}$ ) connected to a computer. Mice were placed in the center of the chamber and allowed to explore for $9 \mathrm{~min}$. Ambulatory distances, time spent and distance traveled in the center of the arena were measured with Viewpoint software.

\section{Splash test}

ST was carried out in a fresh cage as before [35], where mice were individually sprayed on their back twice with $20 \%$ sucrose solution in water and placed in a corner of their home cage. The latency to start grooming was manually recorded.

\section{Novelty-suppressed feeding}

NSF was done in a plastic box $[50 \times 80 \times 20 \mathrm{~cm}]$ with the floor covered with $3 \mathrm{~cm}$ of wooden bedding. $24 \mathrm{~h}$ before testing, mice were food deprived in their home cage. Mice were individually weighed before and after food deprivation to determine \% weight loss. During the test 2 food pellets were placed on a circular white filter paper $(12 \mathrm{~cm}$ diameter) located in the center of the arena. Mice were placed in a corner of the box and latencies to approach pellets and feed were recorded [20]. After the test, the weight of pellet consumption in the home cage during 5 min was registered.

\section{Forced-swim test}

FST was carried out in a glass cylinder $(40 \mathrm{~cm} \times 20 \mathrm{~cm}$ diameter $)$ filled half-way with water $\left(23-24^{\circ} \mathrm{C}\right)$. Mice were tested over 2 days for 6 min each day after which they were dried and returned to their home cages. All swim sessions were videotaped and time of immobility during the second day session was quantified [20].

\section{Locomotor activity}

Mice were introduced into a circular corridor $(4.5 \mathrm{~cm}$ width, $17 \mathrm{~cm}$ diameter) equipped with four infrared beams equidistantly located every $90^{\circ}$ (Imetronic, Pessac, France). Locomotor activity was recorded for $30 \mathrm{~min}$ [20].

\section{Statistical analyses}

Sample size was established by previous pilot and published studies. Mice of each genotype/sex were randomly assigned to different studies. Data distribution was controlled for normality by Q-Q plots, and when ANOVA was applied the homogeneity of variances of the data was tested. For array tomography, the results obtained from two stacks were averaged to generate a mean value per mouse. Data were analyzed using multifactorial ANOVA or two-tailed Student's t-test, using Prism 6 and IBM SPSS 20. Data are expressed as mean \pm SEM. Significance was established at $p<0.05$.

\section{RESULTS}

5-HTR7 is expressed in PFC-SERT+ neurons during early postnatal development

The neurons of the PFC that transiently express SERT during early postnatal mouse development constitute a very specific subpopulation of glutamate projection neurons of layers 5 and 6 . To determine which 5-HTRs are present in PFC-SERT+ neurons, we analyzed data obtained in a previous RNA sequencing study of FACS-isolated PFC-SERT+ neurons at P7 [20]. This analysis indicated that the 5-HTR7 has the highest expression in PFCSERT+ neurons, followed by the 5-HTR1F, 5-HTR5A, and 5-HTR1D, whereas other classical cortical receptor subtypes like the 5-HTR1A or 5-HTR2A have only a minor expression (Fig. 1a). Real-time quantitative PCR (qPCR) studies corroborated the coincidence of
5-HTR7 and SERT expression in the PFC at P7 (Fig. 1b). Furthermore, extended qPCR analysis at different postnatal ages showed that 5-HTR7 mRNA is already present in the PFC by P1, that this expression increases by $\mathrm{P} 7$ and peaks at $\mathrm{P} 14$, with a moderate reduction by P60 (Fig. 1b). In situ hybridization (ISH) results revealed layer-specific expression profiles in the PFC, indicating that 5-HTR7 is abundantly expressed in cortical neurons of layer 2 and layers 5-6 at P0, P7 and P14 (Fig. 1C, C'; Supplementary Fig. S1). However, at later ages (P21), the 5-HTR7 mRNA expression decreased substantially in deep layers, while expression in layer 2 remained moderate (in the mPFC) (Fig. 1d, d'; Supplementary Fig. S1) to high (in the anterior cingulate cortex) (Supplementary Fig. S1). To further explore the 5-HTR7 and SERT co-expression in PFC-SERT+ neurons, we performed double labeling fluorescent ISH. This study showed robust 5-HTR7 and SERT co-expression in cortical neurons of layers 5 and 6 at P7 (Fig. 1e, f). We found that $40 \%$ of SERT+ neurons in the deep layers of the MPFC contain 5-HTR7 transcripts, indicating the presence of a subpopulation of SERT+ neurons expressing the receptor by $\mathrm{P7}$. In addition, a similar proportion of 5-HTR7expressing neurons within the same cortical region contained SERT transcripts (Fig. 1g). Overall, these observations indicated that 5-HTR7 is expressed in the MPFC, with a strong transient expression in deep cortical layers during the first weeks of postnatal life, and is co-expressed with SERT in these neurons.

\section{5-HTR7 regulates the PFC-to-DRN circuit assembly}

Fluoxetine (FLX) exposure during a critical period of postnatal age (P2-P14) produces an increased number of PFC glutamatergic synapses onto 5-HT and GABA neurons in the dorsal raphe nucleus (DRN) [20]. To determine whether 5-HTR7 is involved in this effect, we examined the consequences of 5-HTR7 loss and gain of function. The synaptic density of PFC glutamatergic inputs to the DRN was measured by the high-resolution immunofluorescence technique array tomography [38]. This microscopy technique allows identifying cortical axon terminals containing the vesicular glutamate transporter type 1 (VGLUT1) [37, 38]. Cortical afferents to the DRN arise mainly from the PFC [39-41]. Because of this, VGLUT1 immunolabelling can be used as a readout of PFC synaptic afferents, together with the co-labeling of synapsin 1a, a general marker for synaptic boutons [37, 42]. In addition, tryptophan hydroxylase (TPH) immunolabeling determines the presence of morphological contacts of synaptic boutons to 5-HT neurons [37, 42] (Fig. 2a, b). Array tomography quantitative analyses of VGLUT1/synapsin double labeled puncta in $5-\mathrm{HTR7}^{-1-}$ mice $(38,900$ puncta analyzed) showed a significant reduction of $18 \%\left(t_{8}=2.680 ; p<0.03\right)$ compared with littermate controls (5-HTR7 ${ }^{-1+}$ mice; 29,938 puncta analyzed) (Fig. 2c, d), suggesting a role in PFC-to-DRN circuit formation of 5-HTR7. The analysis of VGLUT1/synapsin double labeled boutons onto 5-HT neurons showed a non-significant trend to decrease, suggesting that total changes observed (Fig. 2d) would have a preferential impact on non-5-HT neurons of the DRN (Fig. 2e; a total of 11,025 and 8,553 puncta analyzed for $5-\mathrm{HTR}^{-1+}$ and $5-\mathrm{HTR}^{-/-}$mice, respectively).

To further interrogate the role of 5-HTR7 in the development of PFC neurons we selectively over-expressed the full length 5-HTR7 with the C-terminal fused to GFP under the control of the synapsin promoter [33]. Previous studies from our group showed that this promoter preferentially drives AAV transduction in pyramidal glutamate projection neurons of the MPFC [35]. Bilateral injections of AAV8-hSyn-5-HTR7-EGFP in the PFC were done at P1 (Fig. 3a). Histological control showed expression exclusively in the frontal pole including orbital, prelimbic and infralimbic regions of the PFC, with a large number of transduced neurons in layer 5-6 neurons at P7 (Fig. 3b). The GFP-labeling was concentrated in the neuronal membranes, within the somatodendritic compartment (Fig. $\left.3 c, c^{\prime}\right)$, and in dendritic spines (Fig. $3 c^{\prime \prime}$ ) as well as well as in 


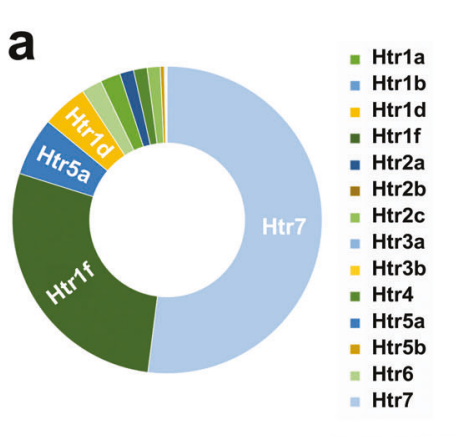

b
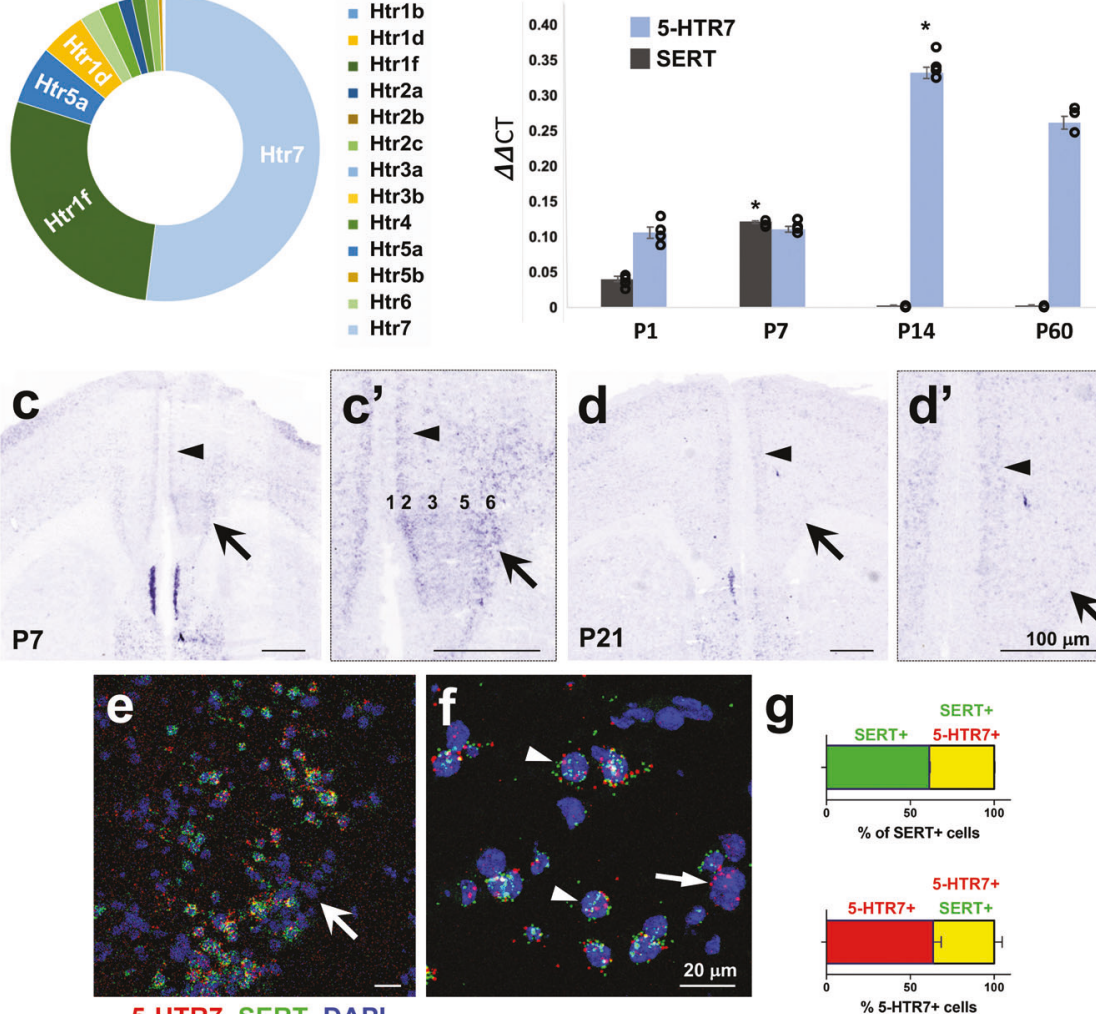

5-HTR7 SERT DAPI

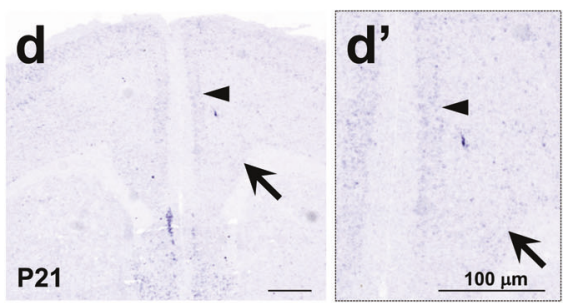

Fig. 1 5-HTR7 expression in the mouse $\mathrm{MPFC}$ is developmentally regulated during the early postnatal period. a Relative proportion of 5HT receptor genes $\left(H\right.$ tr) expressed in PFC-SERT + neurons at P7, as revealed by RNA sequencing profiling of FACS-isolated SERT ${ }^{\text {Cre.:EGFP }}$ neurons from the mPFC. b Time course of 5-HTR7 and SERT mRNA expression by q-PCR on mPFC tissue dissected at P1, P7, P14 and P60 $(n=$ 3-4 per age). ${ }^{*} p<10^{-6}$ for SERT at P7 vs. all ages $\left(F_{3,7}=314.103 ; p<10^{-7}\right)$, and 5 -HTR7 at P14 vs. P1-P7 $\left(F_{3,7}=129.497 ; p<10^{-5}\right)$ after ANOVA followed by Tukey's test. c, $\mathbf{d}$ In situ hybridization of 5-HTR7 in the MPFC at P7 (c, $\left.c^{\prime}\right)$ and P21 (d, d') illustrating a laminar shift in the distribution of the receptor during the early postnatal period. Abundant expression of 5-HTR7 is present in layers 5-6 at early ages (arrows), however by P21 this expression remains only in superficial 2-3 layers (arrowheads). e, $\mathbf{f}$ RNAscope double fluorescent in situ hybridization in the mPFC at P7 (e, arrow), showing nuclear (DAPI, blue) co-localization of 5-HTR7 mRNA (red) with SERT mRNA (green) expression (arrowheads). Some of these mPFC neurons present 5-HTR7 mRNA but not SERT expression (f, arrow). $\mathbf{g}$ Quantitative analysis of the percentage of mPFC neurons coexpressing SERT (green) and 5-HTR7 (red) mRNAs.

PFC efferent axons. Importantly, in the brainstem, labeling was noted in axon terminals within the DRN, in close proximity to $5-\mathrm{HT}$ labeled neurons (Fig. $3 d, d^{\prime}$ ). Next, we corroborated the virallyinduced over-expression levels of the 5-HTR7 mRNA in the PFC by qPCR at P7. The viral construct over-expressed the 5-HTR7 mRNA about 25 times above the expression levels of sham controls (injected with AAV-9-hSyn-EGFP-WPRE-bGH). Further, such increase in 5-HTR7 expression levels was not longer evidenced in adulthood (Supplementary Fig. S2). Using these tools, we observed that 5-HTR7 over-expression in the PFC caused a significant increase in the density of VGLUT1/synapsin double labeled puncta in the DRN when compared with sham control mice $\left(\mathrm{t}_{8}=6.185 ; p<0.0003\right.$ ) (a total of 54,922 and 34,267 puncta analyzed for 5-HTR7-over-expressing and sham mice, respectively) (Fig. 3e). This effect was also evident when analyzing the double labeled synaptic puncta in morphological contact with TPHpositive neurons $\left(t_{8}=5.895 ; p<0.0004\right)(17,763$ and 8735 puncta analyzed for 5-HTR7-overexpressing and sham mice, respectively) (Fig. 3f).

Next, we asked whether antagonizing the 5-HTR7 may prevent the morphological synaptogenic effects of FLX exposure during the postnatal critical period. Wild-type mouse pups were administered with FLX or saline, alone or together with the selective 5-HTR7 antagonist SB269970 [31] daily from P2 to P14
(Fig. 3g). Two-way ANOVA results showed no significant interaction between FLX/SAL treatment and SB269970 treatment $\left(F_{1,14}=\right.$ $0.890 ; p=0.36)$. Confirming our previous observations, the density of VGLUT1/synapsin double labeled terminals was increased in the FLX-treated mice when compared with the saline-treated controls (Main Effects: $F_{1,14}=16.773 ; p<0.001$ ) (Fig. 3h). This difference was abolished when SB269970 was co-administered with FLX or SAL (Main Effects: $F_{1,14}=3.934 ; p=0.067$ ) (Fig. 3h). Similarly, associations of VGLUT1+ synaptic boutons with TPH-positive neurons were also increased by FLX treatment (Main Effects: $F_{1,14}=8.877 ; p<0.01$ ), but these differences disappeared when administering SB269970 (Main Effects: $F_{1,14}=4.198 ; p<0.06$ ) (Fig. 3i).

Overall, these experiments indicate that 5-HTR7 controls the formation of efferent PFC projections to the brainstem DRN during early postnatal life, highlighting the requirement of 5-HTR7 for the morphogenetic effects of postnatal FLX exposure on the PFC-toDRN synaptic circuit.

5-HTR7 engagement in shaping adult emotional behaviors

To assess the developmental role of 5-HTR7 in adult emotional phenotypes, we generated new cohorts of the different experimental groups described above to examine behavioral effects in adulthood, focusing on anxiogenic and depressive-like behaviors. 

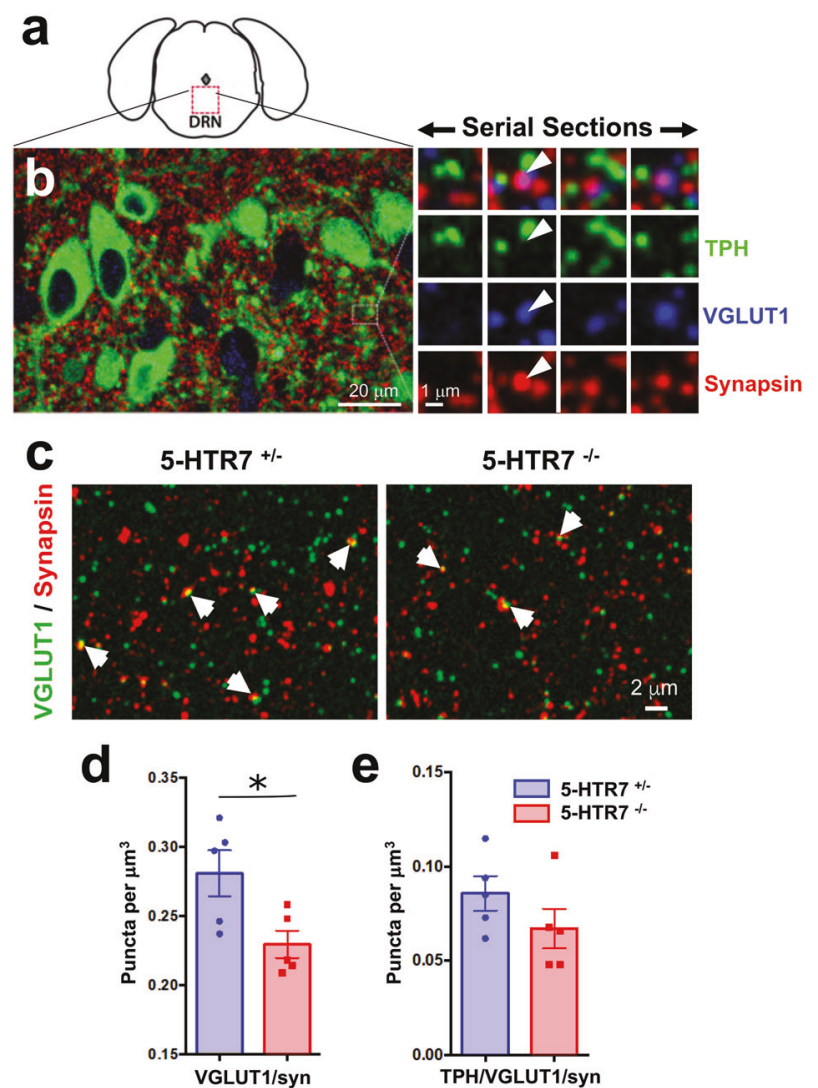

Fig. 2 Genetic ablation of the 5-HTR7 diminishes the synaptic afferents of the PFC-to-DRN circuit. a Diagram indicates the region sampled for the array tomography quantitative analysis. b Array tomographic render from seven $100 \mathrm{~nm}$ thick sections immunolabeled for tryptophan hydroxylase (TPH, green), synapsin (red) and the vesicular glutamate transporter type (VGLUT1, blue). The zoomed-in area in the right panel shows four serial sections in which VGLUT1 and synapsin co-label the same axon bouton (arrowhead), in close apposition to TPH + neuronal profiles. c Representative high-resolution array tomography image of double labeled puncta against VGLUT1 and synapsin (arrows) in a $100 \mathrm{~nm}$ thick section of the DRN from $5-\mathrm{HTR7}^{+1-}$ and $5-\mathrm{HTR7}^{-1-}$ mice. Quantitative analysis of PFC glutamatergic synaptic afferents in the DRN of $5-\mathrm{HTR7}^{+/-}$and $5-\mathrm{HTR7}^{-1-}$ mice. All VGLUT1/synapsin + puncta $\left(t_{8}=2.680 ; p<0.03\right)(\mathbf{d})$, and VGLUT1/synapsin + puncta in contact with TPH + neurons $\left(t_{8}=1.348 ; p=0.22\right)(\mathbf{e})$ are shown.

Heterozygous breeding was used to generate cohorts of $5-\mathrm{HTR7}{ }^{+/+}$; $5-\mathrm{HTR}^{+-}$and $5-\mathrm{HTR}^{-1-}$ mice. Adult behavioral testing of these mice did not reveal genotype effects in any of the tests used: locomotor activity, exploration of an open arena (OF), latency to groom in the splash test (ST), latency to feed in the novelty suppressed feeding (NSF), and immobility time in the forced swim test (FST) (Supplementary Fig. S3). These observations confirmed the lack of an anxiety phenotype of the $5-\mathrm{HTR}^{-/-}$ mice, but did not reproduce the reduced immobility time in the FST observed in previous studies $[26,43]$. Next, we asked whether the 5-HTR7 could have a role in the adult emotional alterations induced by postnatal exposure to FLX. To this end, $5-\mathrm{HTR} 7^{-1-}$ and $5-\mathrm{HTR7}^{+/-}$mice were administered with FLX or vehicle from P2 to P14 (Fig. 4a). Two-way ANOVA results showed no interaction between genotype and treatment factors in the total distance traveled in the OF $\left(F_{1,72}=2.656 ; p=0.108\right)$ (Fig. $\left.4 \mathrm{~b}\right)$. In contrast, FLX-treated mice showed decreased exploration of the arena (Main Effects: $F_{1,72}=17.606 ; p<0.0001$ ), with a robust genotype effect (Main Effects: $F_{1,72}=7.406 ; p<0.008$ ) (Fig. $4 b$ ). The results of time spent in the center of the OF arena showed a significant genotype $x$ treatment interaction $\left(F_{1,72}=3.978 ; p<0.05\right)$. Simple effects indicated a reduction in the time exploring the center of the arena only in FLX-treated $5-\mathrm{HTR7}^{+/-}$mice in comparison to control treated littermates $\left(F_{1,28}=10.954 ; p<0.003\right)$. (Fig. $\left.4 c\right)$. No differences between treatments or genotypes were observed in total distance traveled in the center (Supplementary Fig. S4a). Analysis of latency to groom in the ST showed a non-significant factor interaction $\left(F_{1,72}=0.002 ; p=0.96\right)$. However, FLX treatment increased the latency to groom (Main Effects: $F_{1,72}=22.385$; $p<0.0001$ ) (Fig. 4d), and these differences appeared more pronouncedly in $5-\mathrm{HTR}^{+/-}$mice, however this effect did not reach significance (Main Effects: $F_{1,72}=0.053 ; p=0.82$ ). Similarly, in the NSF, we did not find a significant factor interaction $\left(F_{1,72}=2.777\right.$; $p=0.10)$. In contrast, FLX-treated mice showed an increased latency to feed (Main Effects: $F_{1,72}=13.619 ; p<0.0004$ ) (Fig. 4e), and this effect was more robust in $5-\mathrm{HTR}^{+/-}$mice, although not significant (Main Effects: $F_{1,72}=3.596 ; p=0.06$ ). On the other hand, we did not find changes in the percentage of weight loss or food consumption in the home cage among experimental groups (Supplementary Fig. S4b,c). Evaluation of the floating time in the FST also showed a non-significant interaction $\left(F_{1,72}=2.540\right.$; $p=0.12)$. In this case, FLX-treated mice showed an increase in the floating time (Main Effects: $F_{1,72}=13.209 ; p<0.001$ ) that was more evident in $5-\mathrm{HTR}^{+/-}$mice (Fig. $4 \mathrm{f}$ ), although did not reach statistical significance (Main Effects: $F_{1,72}=1.035 ; p=0.31$ ). Locomotor activity in a circular path was not affected either by the treatment or genotype (Interaction: $F_{1,72}=0.023 ; p=0.88$; Main Effects treatment: $F_{1,72}=0.451 ; p=0.50$; Main Effects genotype: $F_{1,72}=2.414$; $p=0.13$ ) (Fig. 4g).

Because experiments in $5-\mathrm{HTR}^{-1-}$ mice do not allow assessing the tissue-specific spatiotemporal requirement of 5-HTR7 expression, we used the viral over-expression approach described previously to specifically interrogate the developmental role of PFC 5-HTR7 in shaping adult emotional behaviors. We compared adult mice that had been injected at P1 with the viral construct encoding for 5-HTR7-GFP, with those injected with the viral construct encoding only for the GFP reporter (Fig. 4h). Behavioral analysis of these mice revealed a reduced exploration and time spent in the center of the arena in the OF $\left(t_{26}=6.222 ; p<0.0001\right.$ and $t_{26}=3.638 ; p<0.002$, respectively) (Fig. $4 \mathrm{i}, \mathrm{j}$ ), without changes in distances traveled in the center (Supplementary Fig. S4d). In addition, increased latency to groom in the ST $\left(t_{26}=6.145 ; p<\right.$ $0.0001)$ (Fig. $4 \mathrm{k})$ and to feed in the NSF $\left(t_{26}=3.082 ; p<0.005\right)$ (Fig. 4l) were also observed. In the NSF, no differences in body weight before and after the testing session, or in home cage pellet consumption, were registered (Supplementary Fig. S4e,f). In the FST, increases in floating times were found $\left(\mathrm{t}_{26}=4.411 ; p<0.0002\right)$ (Fig. $4 \mathrm{~m}$ ). In contrast, no changes in locomotor activity were noted among experimental groups $\left(t_{26}=0.480 ; p=0.64\right)$ (Fig. $\left.4 n\right)$.

Altogether, our results uncover a crucial role of 5-HTR7 in the developmental effects of FLX on adult anxiety and depressive-like behavior. Moreover, our findings indicate that the transient presence of 5-HTR7 in the PFC during early postnatal life is sufficient to largely replicate emotional alterations induced by FLX at this time period.

Developmental 5-HTR7 blockade prevents detrimental paradoxical effects of SSRIs on emotional behavior

Next, we evaluated the potential benefit of antagonizing the 5HTR7 during the postnatal FLX treatment to prevent the detrimental long-term effects on emotional behaviors. For this purpose, the specific 5-HTR7 antagonist SB269970 was coadministered with FLX during the critical period (from P2 to $\mathrm{P} 14$ ) in wild-type mice and emotional behaviors were investigated in adulthood (Fig. 5a). Two-way ANOVA results of the total distance traveled in the OF showed a non-significant interaction between FLX/SAL and SB269970 treatments $\left(F_{1,52}=1.463 ; p=\right.$ 0.232 ). Consistent with previous studies, FLX treatment decreased 

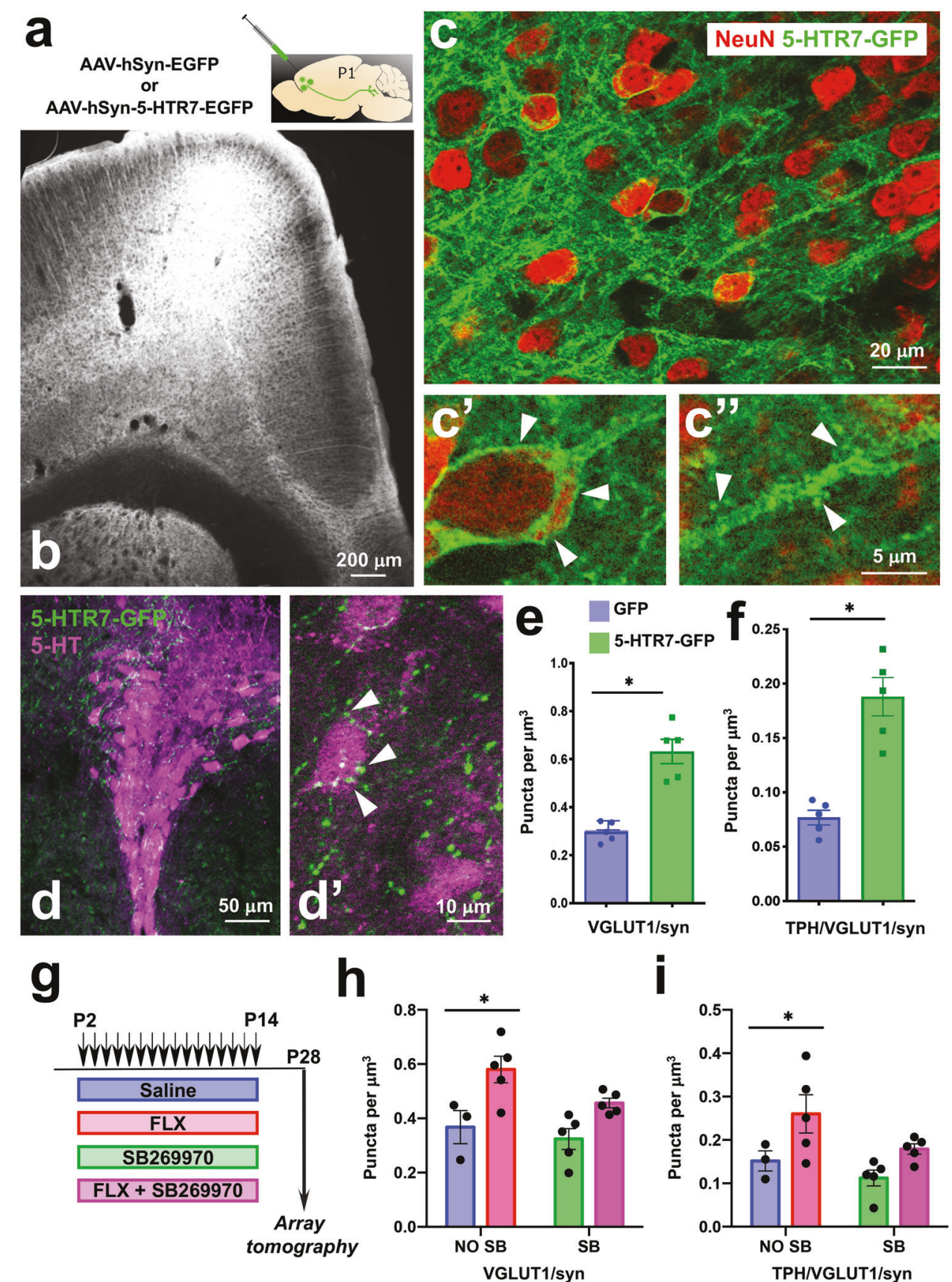

Fig. 3 Developmental role of 5-HTR7 in the synaptic wiring of the PFC-to-DRN circuit. a, b Bilateral injections of the AAV-hSyn-5-HTR7-EGFP or AAV-hSyn-EGFP were carried out in the PFC of C57BL/6 mice at P1. Coronal section through the PFC at P12 shows heavy 5-HTR7-GFP expression in deep cortical layers (b). c High power confocal images of pyramidal neurons expressing the construct encoding 5-HTR7-GFP (green) with NeuN counterstaining (red). The 5-HTR7-GFP localizes at the cell membrane of pyramidal cell somas (c') and dendritic processes including spines $\left(\mathbf{c}^{\prime \prime}\right)$. 5-HTR7-GFP labeling is visible in axon terminals in the DRN (green) (d), often associated with TPH + neurons (5-HT, magenta) (d'). Quantification of VGLUT1/synapsin + axonal boutons in the DRN of P28 mice that received injections of either sham (GFP; $n=5)$ or 5-HTR7-EGFP $(n=5)$ viral constructs in the PFC at P1. All VGLUT1/synapsin+ puncta (e), and VGLUT1/synapsin+ puncta in contact with TPH+ neurons (f) are shown. ${ }^{*} p<0.001$. g-i Four groups of C57BL/6 mice were administered subcutaneously with saline $(n=3)$, FLX $(10 \mathrm{mg} / \mathrm{kg} /$ day; $n=5)$, FLX $(10 \mathrm{mg} / \mathrm{kg} /$ day $)+$ SB269970 $(10 \mathrm{mg} / \mathrm{kg} / 12 \mathrm{~h})(n=5)$ or SB269970 $(10 \mathrm{mg} / \mathrm{kg} / 12 \mathrm{~h} ; n=5)$ during the critical period (P2-P14). Array tomography quantitative analyses were carried out in the DRN at P28 in all four experimental groups (g). Density of VGLUT1/synapsin + puncta (h) [total number of puncta analyzed for saline $(21,510)$, FLX $(45,166)$, FLX+ SB269970 $(35,215)$ and SB269970 alone $(26,892)$ ], and VGLUT1/synapsin + puncta related to TPH + neurons (i) [total number of puncta analyzed for saline (7059), FLX (20,011), FLX+ SB269970 $(14,563)$ and SB269970 alone (8907)]. ${ }^{*} p<0.001$ and $p<0.01$ for $\mathbf{h}$ and $\mathbf{i}$, respectively, FLX vs. all treatments.

the exploration in the OF in comparison to saline-treated mice (Main Effects: $F_{1,52}=23.289 ; p<0.0001$ ) (Fig. 5b), and this effect was not evident after SB269970 co-administration (Main Effects: $F_{1,52}=0.808 ; p=0.37$ ) (Fig. 5b). Time spent in the center of the arena showed an apparent interaction between treatments that did not reach significance $\left(F_{1,52}=3.985 ; p=0.0512\right)$. Consistent to what happened with total distance traveled, FLX treatment decreased the time spent in the center (Main Effects: $F_{1,52}=$ 7.708; $p<0.008$ ), and this reduction was not longer visible when SB269970 was co-administered (Main Effects: $F_{1,52}=1.235$; 
a
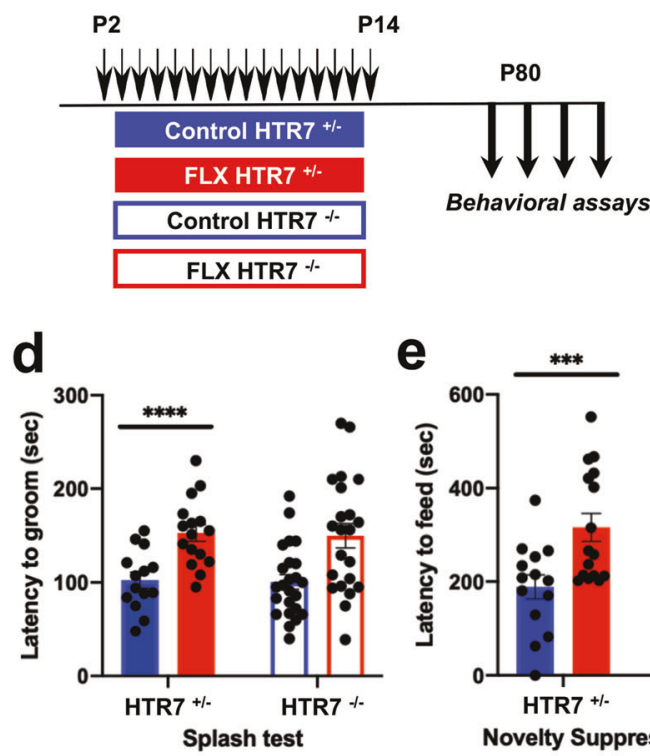

h
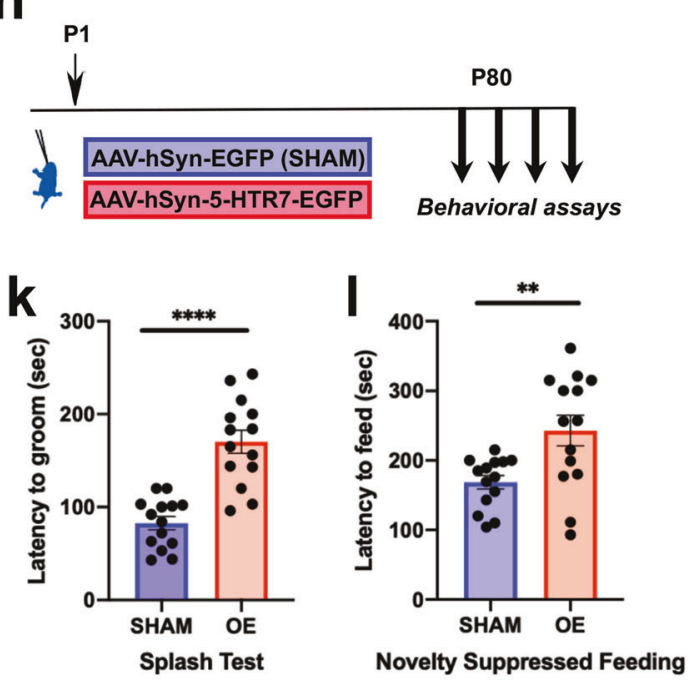
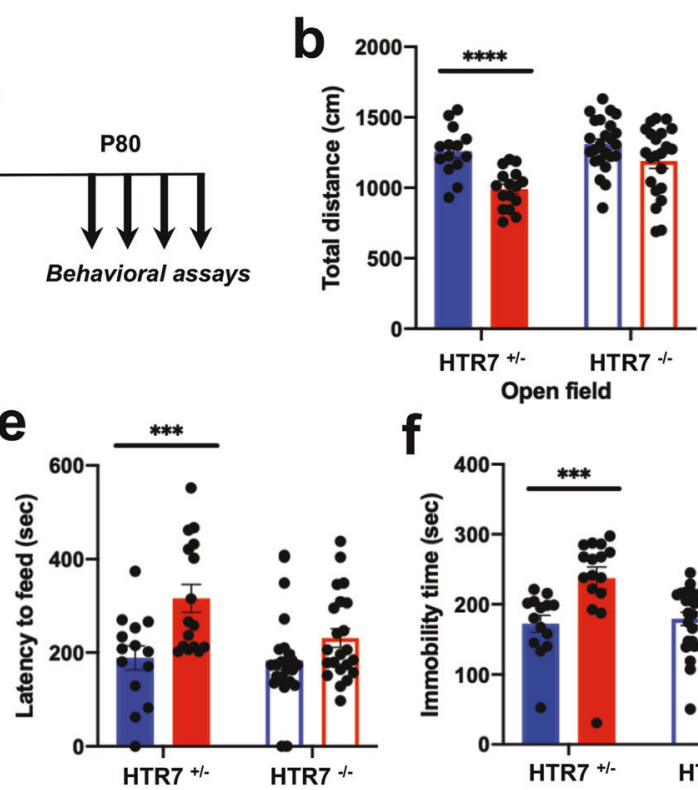

Novelty Suppressed Feeding f

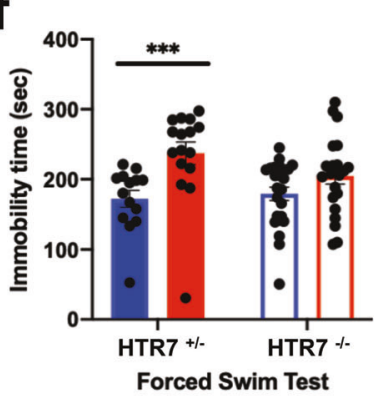

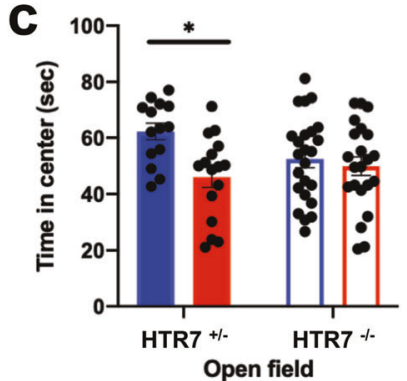

g
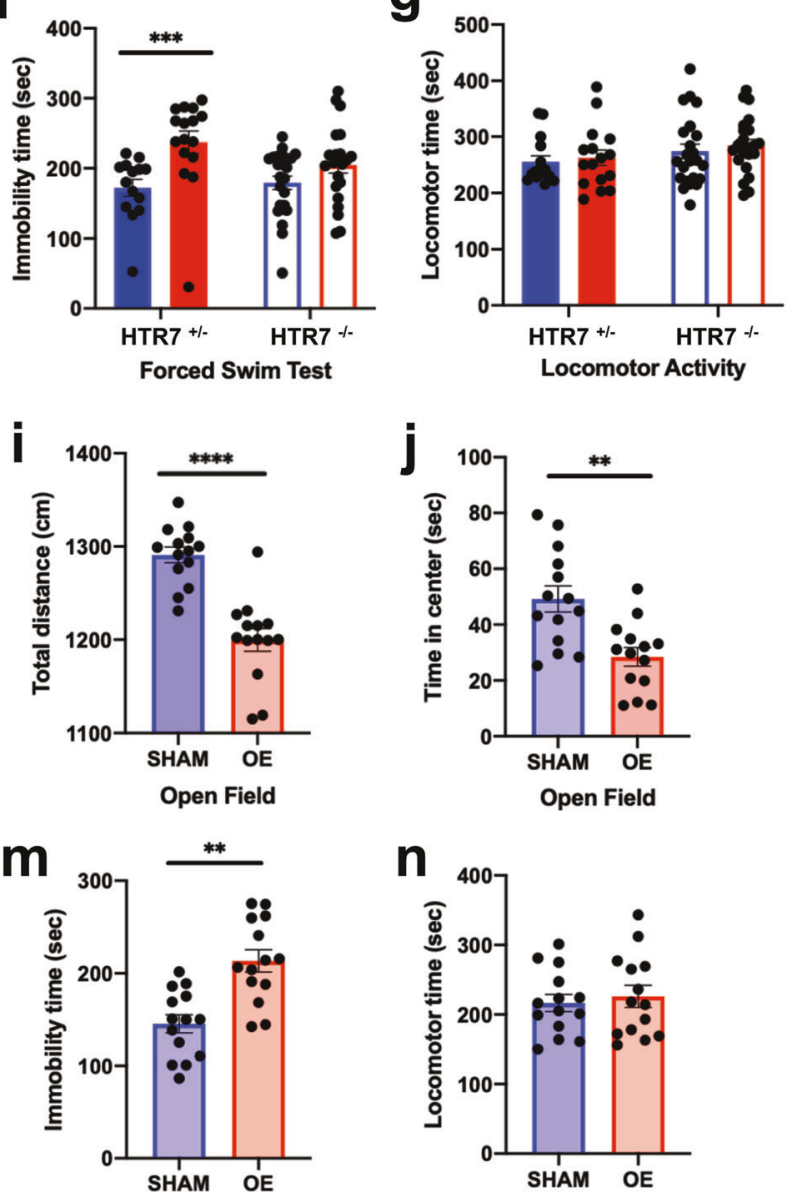

Forced Swim Test

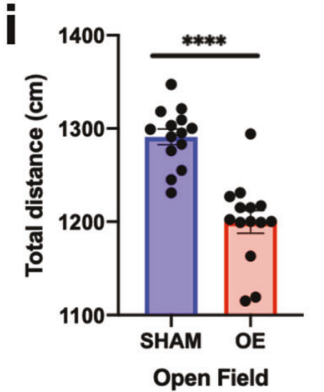

and $5-\mathrm{HTR7}^{-1-}$ mice were treated orally with FLX Fig. 4 Engagement of 5-HTR7 in shaping adult emotional behaviors. a $5-H T R 7^{+/-}$and $5-H T R 7^{-1}$ mice were treated orally with $\mathrm{FLX}$
$\left(10 \mathrm{mg} / \mathrm{kg} /\right.$ day in $3 \%$ sucrose solution; $n=16$ and $n=22$ for $5-\mathrm{HTR} 7^{+/-}$and $5-\mathrm{HTR} 7^{-1}$ mice, respectively) or vehicle (3\% sucrose solution;
$n=14$ and $n=24$ for $5-H T R 7^{+/-}$and $5-\mathrm{HTR} 7^{-/-}$mice, respectively) during the critical period (P2-P14), to evaluate emotional behaviors in the $n=14$ and $n=24$ for $5-H T R 7^{+/-}$and $5-H T R 7^{-1-}$ mice, respectively) during the critical period (P2-P14), to evaluate emotional behaviors in the
adulthood (from P80). b Total distance traveled in the Open Field test (OF) (Main Effects treatment: $F_{172}=17.606 ; p<0.0001$ ), and time spent in the center of the arena (c) (Interaction treatment $x$ genotype: $F_{1,72}=3.978 ; p<0.05$ in $5-\mathrm{HTR} 7^{+/ 2}$ mice, FLX vs. control: $F_{1,28}=10.954$; $p<0.003$ ). d Latency to groom in the Splash Test (ST) (Main Effects treatment: $F_{1,72}=22.385 ; p<0.0001$ ). e The latency to feed in the Novelty Suppressed Feeding Test (NSF) (Main Effects treatment: $\left.F_{1,72}=13.619 ; p<0.0004\right)$. f Immobility time in the Forced Swim Test (FST) (Main Effects treatment: $F_{1,72}=13.209 ; p<0.001$ ). g Locomotor activity in a circular path (Main Effects treatment: $F_{1,72}=0.451 ; p=0.50$ ). $\mathbf{h}$ C57BL/6 mice were bilaterally injected with AAV-hSyn-5-HTR7-EGFP (OE; $n=14$ ) or AAV-hSyn-EGFP (Sham; $n=14$ ) in the PFC at P1. Behavioral measurements were carried out in these mice in the OF (i, j), ST (k), NSF (I) and FST (m), and locomotor activity $(\mathbf{n})$, starting at P80. ${ }^{* *} p<0.005$ and ${ }^{* * * *} p<0.0001$ in $\mathbf{i}-\mathbf{n}$.

$p=0.27$ ) (Fig. 5c). Total distance traveled in the center was not changed among all the experimental groups (Supplementary Fig. S4g).

In the ST, there was a significant interaction between both treatment factors $\left(F_{1,52}=20.406 ; p<0.0001\right)$. Simple effects showed that the increased latency to groom produced by FLX when compared with control mice $\left(F_{1,24}=29.856 ; p<0.0001\right)$ was completely prevented by concomitant treatment with SB269970
$\left(F_{1,25}=11.982 ; p<0.002\right)$ (Fig. $\left.5 d\right)$. Interestingly, a less marked but significant increase in the latency to groom was observed in mice that had SB269970 alone $\left(F_{1,27}=8.401 ; p<0.007\right)$ (Fig. $\left.5 d\right)$.

In the NSF we found a significant factor interaction in the latency to feed $\left(F_{1,51}=9.518 ; p<0.003\right)$. Simple effect analyses showed that FLX increase in the latency to feed respect to saline controls $\left(F_{1,23}=15.845 ; p<0.001\right)$, was prevented by SB269970 co-administration $\left(F_{1,25}=17.082 ; p<0.0004\right)$ (Fig. $\left.5 \mathrm{e}\right)$. On the 

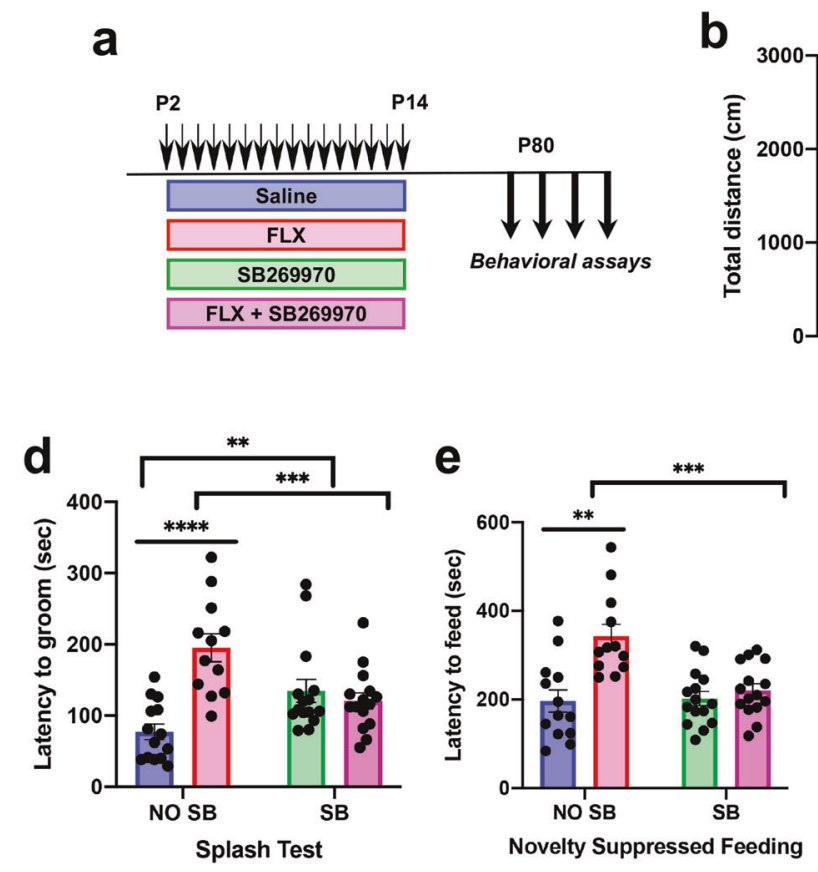
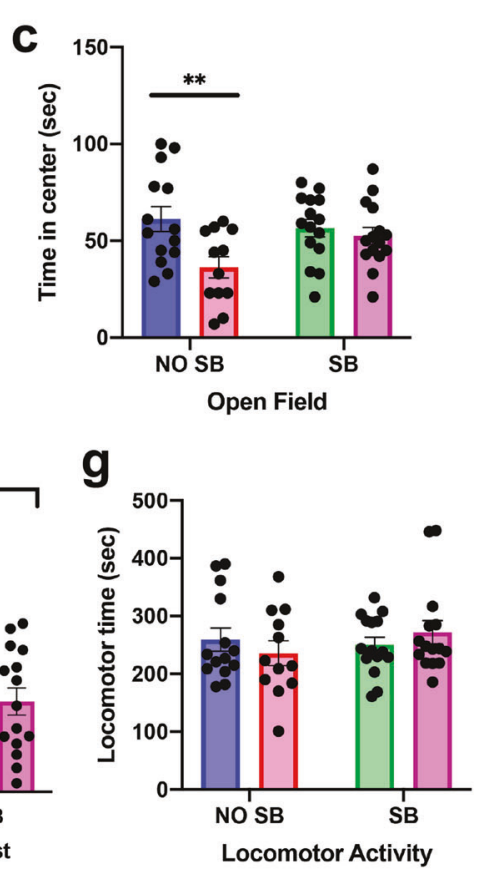

Fig. 5 Developmental 5-HTR7 blockade prevents detrimental paradoxical effects of SSRIs on emotional behavior. a Four groups of C57BL/ 6 mice were administered subcutaneously with saline $(n=14)$, FLX $(10 \mathrm{mg} / \mathrm{kg} / \mathrm{day} ; n=12), \mathrm{FLX}(10 \mathrm{mg} / \mathrm{kg} / \mathrm{day})+\mathrm{SB} 269970(10 \mathrm{mg} / \mathrm{kg} / 12 \mathrm{~h})(n=$ 15), or SB269970 alone (10 mg/kg/12 h; $n=15)$ during the critical period (P2-P14) to evaluate adult emotional behaviors (from P80). Total distance traveled in the OF (b) (Main Effects SAL/FLX treatment: $F_{1,52}=23.289 ; p<0.0001$ ), and time spent in the center of the arena (c) (Main Effects SAL/ FLX treatment: $\left.F_{1,52}=7.708 ; p<0.008\right)$. Latency to groom in the ST (d) (FLX/SAL x SB269970 treatment interaction: $\left.F_{1,52}=20.406 ; p<0.0001\right)$, latency to feed in the NSF (e) (FLX/SAL $x$ SB269970 treatment interaction: $\left.F_{1,51}=9.518 ; p<0.003\right)$, and immobility time in the FST (f) (FLX/SAL $x$ SB269970 treatment interaction: $\left.F_{1,52}=26.952 ; p<0.0001\right)$. Locomotor activity $(\mathbf{g}) .{ }^{* *} p<0.01,{ }^{* *} p<0.002$, and ${ }^{* * * *} p<0.0001$.

other hand, no differences in body weight or in home cage pellet consumption were registered (Supplementary Fig. S4h, i).

Two-way ANOVA of the FST data showed a significant factor interaction $\left(F_{1,52}=26.952 ; p<0.0001\right)$. Simple effect ANOVAs showed that increased floating time produced by FLX exposure respect to saline controls $\left(F_{1,24}=18.646 ; p<0.0002\right)$ was prevented by SB269970 co-administration $\left(F_{1,25}=17.668 ; p<0.0003\right)$ (Fig. 5f). In addition, similarly to what happened in the ST, an increased immobility time was observed in saline controls after SB269970 developmental treatment $\left(F_{1,27}=9.716 ; p<0.004\right)$, suggesting a direct selective impact on depressive-like phenotypes (Fig. 5f). No treatment effects were detected in locomotor activity among all groups (Fig. $5 \mathrm{~g}$ ).

These results indicate a critical developmental role of 5-HTR7 in mediating the susceptibility to early postnatal FLX during the critical period. Furthermore, our findings demonstrate that concomitant systemic pharmacological antagonism of 5-HTR7 is sufficient to prevent the appearance of detrimental emotional effects caused by FLX in the early life.

\section{DISCUSSION}

This study identifies 5-HTR7 as a major player in prefrontal circuit development during the early postnatal period, with impact on adult emotional behaviors. We demonstrate that both morphological and behavioral consequences of a developmental exposure to SSRIs are dependent on the activation of the 5-HTR7 in the PFC. Importantly, the depressive-like and anxiety phenotypes caused by developmental FLX exposure can be prevented by the coadministration of a selective 5-HTR7 antagonist, opening interesting leads for modulation of antidepressant drug therapies during child-bearing ages.

In a previous study we identified the transient SERT expression in PFC neurons as an important target for developmental longterm detrimental effects of SSRIs [20]. Here, we found that 5-HTR7 is the 5-HT receptor with the highest expression in those cortical $\mathrm{SERT}+$ neurons during early postnatal development. The transient expression of SERT and 5-HTR7 in the same neurons suggested the existence of a tight temporal control of 5-HT signaling through this receptor during this period. That is, the high affinity uptake of 5-HT mediated by SERT is expected to decrease 5-HT availability for 5-HTR7 at the neuronal cell membrane. Previous localization studies indicated a fairly broad distribution of 5-HTR7 in the adult brain including the cerebral cortex [44], but developmental studies are limited to only few brain regions in the rat $[21,45]$. Our study showed that $5-\mathrm{HTR} 7$ in the PFC has a transient expression in pyramidal neurons of layers 5-6 during the first 3 weeks of life, including SERT+ and SERT- neurons, while the expression in upper cortical layers is stable until adulthood. Consistent with our findings, Béique et al. (2004) showed a dramatic shift in the effects of $5-\mathrm{HT}$ on membrane potential over mPFC postnatal development. Specifically, during the first three postnatal weeks $5-\mathrm{HT}$ induces a rapid depolarization of layer 5 pyramidal cells that can be largely blocked by 5-HTR7 antagonists but not by 5-HTR2A antagonists. Later in development, the characteristic 5-HTR1A-mediated adult hyperpolarization of the same pyramidal neurons produced by $5-\mathrm{HT}$ can be only achieved after the third postnatal week [46, 47]. This shift in the physiological responses could be interpreted as a consequence of 5-HTR7 and 5-HTR1A dimerization, favoring the inhibitory component of the dimer $[48,49]$. However, our data show that the 5-HTR7 expression in deep layer cortical neurons is downregulated by $\mathrm{P} 21$, consistent with electrophysiology studies $[46,47]$.

Transient expression of 5-HTR7 in the PFC coincides with a period of high developmental plasticity. Pyramidal neurons of layers 5-6 in the mPFC send subcortical projections to a number of targets including the basal ganglia, amygdala, hypothalamus, and brainstem [40, 50]. Most of these projections are still undergoing active growth and synaptogenesis in subcortical 
targets during the first weeks of postnatal life. In particular, brainstem-projecting PFC neurons increase their inputs to the DRN establishing supernumerary excitatory synapses onto 5-HT and GABA neurons up to P21 [20]. The present experiments indicate that 5-HTR7 is an important player to modulate this synaptogenesis, since over-expression in the PFC increased the number of glutamatergic synapses in the DRN, while $5-\mathrm{HTR}^{-1-}$ mice had a reduced synaptic density. However, the chronic developmental application of the 5-HTR7 antagonist SB269970 alone did not modify the number of PFC glutamate synaptic afferents to the DRN. A possible interpretation of this difference is that in our pharmacological experiments the 5-HTR7 is only partially blocked to the actions of $5-\mathrm{HT}$, especially when considering the narrow window of action of the SB269970 [31]. However, this partial action appeared sufficient to counterbalance the overgrowth of cortical glutamatergic synapses in the DRN produced by developmental exposure to FLX. It should be noted that estimates of glutamatergic synapses measured with array tomography could be affected by decreases in VGLUT1/synapsin expression levels. However, previous studies indicate a highly consistent electrophysiological functional correlate of the morphological synaptic measurements including those produced by developmental exposure to FLX $[20,37,51]$.

5 -HT is well known to have multiple morphogenetic roles, which differ according to 5-HT receptors and cell types [3, 52, 53]. Several in vitro studies concur to show that 5-HTR7 activation has a trophic effect, as 5-HTR7 agonists increased axon growth and synaptogenesis in hippocampal and striatal primary cultures $[21,23,53]$. The present study provides the first demonstration of an in vivo physiological effect of 5-HTR7 on a well-defined neural circuit. Compared with previous studies that focused on dendritic spine formation, we reveal here an additional morphogenetic effect on axon terminals, since manipulating 5-HTR7 expression in the PFC was sufficient to cause exuberance of glutamate terminals in the DRN. Moreover, the localization of 5HTR7-GFP fusion protein at PFC axon terminals, strongly argues for a direct effect of 5-HTR7 stimulation at presynaptic sites, in addition to its previously identified postsynaptic effects on dendritic spine formation [21]. It will be interesting in the future to identify the downstream signaling mechanisms of this presynaptic effect, as 5-HTR7 is known to activate both GsCAMP-PKA and Ga12-RhoGAP-CDC42 pathways [21, 23, 53]. Our RNA profiling indicates that players of both pathways are present in the PFC-SERT+ neurons at P7 [20]. On a translational note, the demonstration that 5-HTR7 controls synaptogenesis and neural circuit development in the PFC, offers some interesting mechanistic insights to the proposal of 5-HTR7 gene variants as risk factors in neurodevelopmental psychiatric disorders such as schizophrenia [54] and autism spectrum disorders [55].

Exposure to a variety of SSRIs including FLX during the postnatal period has been repeatedly found to cause anxiety and depressive-like phenotypes later in life $[20,56-58]$. Similarly, genetic models interfering with SERT function such as SERT-KO rodents display paradoxical depressive-like behaviors that can be explained by an increased 5-HT signaling during the first postnatal weeks $[8,59]$. Pharmacological approaches indicated a partial role of the excess of activation of the 5-HTR1A [8] and 5-HTR2A receptors [58] in these effects. The present study provides complementary evidence pointing to a primordial role of the 5HTR7 in the long-term emotional detrimental effects of developmental exposure to SSRIs. Depressive-like symptoms and anxiogenic responses were largely prevented by concomitant pharmacological treatment with a selective 5-HTR7 antagonist, and were substantially reduced in $5-\mathrm{HTR}^{-1-}$ mice receiving postnatal FLX. Interestingly, developmental blockade of 5-HTR7 by SB269970 per se produced adult depressive-like behavior but not anxiety phenotypes, in agreement with previous work showing a developmental effect of other $5-\mathrm{HT}$ receptors like the 5-HTR2A/C in anxiety phenotypes [58]. It will be interesting to determine whether other behavioral symptoms that are due to developmental increases of $5-\mathrm{HT}$, such as sleep disturbances (increase in REM sleep) $[8,57]$ are also dependent on developmental effects of 5-HTR7, as this receptor is strongly expressed in the suprachiasmatic nucleus [44] and involved in the control of circadian rhythms and sleep $[28,60]$.

Present experiments showed that over-expression of the 5HTR7 in PFC neurons was sufficient to induce anxiety and depressive-like symptoms in adulthood. Thus, developmental changes in PFC circuits are likely involved in their occurrence. However, it is difficult at present to pinpoint the relationship between specific circuit changes and emotional phenotypes. The PFC-to-DRN circuit that we focused on is an interesting candidate as it is recruited in stress control mechanisms and its general action appears to be that of dampening of 5-HT neuronal activity [17, 61-63]. Accordingly, stimulation of this pathway has been shown to have antidepressant effects [19], including in the postnatal FLX model [20]. Moreover, it is thought to underlie the beneficial effects of deep brain stimulation in treatment-resistant depressive patients [64]. Based on these studies, the synaptic exuberance of PFC terminals in the DRN can be interpreted as counteracting maladaptive circuit changes in other circuits. In this interpretation it should be noted that the PFC acts as a hub to control emotional behaviors by acting on a large number of brain targets with different outcomes according to targets. For instance top-down influence of the PFC on the midbrain dopaminergic neurons was proposed to cause anhedonia [65].

5-HTR7 antagonists have been proposed as a therapeutic approach in mood disorders [66] and could be an interesting alternative to SSRIs or combined to sub-threshold doses of SSRIs for the treatment of depression during pregnancy or postpartum. Treatment of severe depression in pregnant women remains a conundrum, because of the known risk to depressive mothers but also given the possible consequences of antidepressant treatments on child neurodevelopment [5,67]. Current selective 5HTR7 antagonists have a low bioavailability (because of a short half life and the requirement of parenteral administration) [31]. Interestingly, atypical neuroleptics such as Amisulpride [68] or Lurasidone [69], that have a high affinity for the 5-HTR7 acting as inverse agonists, were noted to have antidepressant effects. However, it remains to be determined whether these compounds would also be efficient mitigating the developmental detrimental consequences of SSRIs, as found here for SB269970.

\section{FUNDING AND DISCLOSURE}

The study was funded by the LabEx BioPsy and the Agence Nationale de la Recherche to PG (ANR-11-0004-02, ERA-NET Respond/ANR-15-0179, ANR-16-0162). JO benefited from a doctoral studentship from École des Neurosciences Paris Île de France. MS-R was supported by a Labex BioPsy fellowship and a 2015 NARSAD Young Investigator Grant from the Brain \& Behavior Research Foundation (\#23742). The authors declare no competing interests.

\section{ACKNOWLEDGEMENTS}

We thank the Imaging and Animal facilities of the Institut du Fer à Moulin, in particular to Gael. We thank Aude Muzerelle for managerial support, Anne Teissier and Nicolas Renier for critical reading of the manuscript.

\section{AUTHOR CONTRIBUTIONS}

$J O, M S-R$, and PG designed the project. JO performed all the experiments and analyzed the data with help of MS-R and PG. The molecular cloning and AAV production were conducted under supervision of IM. The ISH was performed by JO and SD. EPa provided the 5-HTR7 knockout mice, and EPo contributed with 5-HTR7 DNA constructs. JO, MS-R and PG wrote the manuscript with feedback from all the authors. 


\section{ADDITIONAL INFORMATION}

Supplementary Information accompanies this paper at (https://doi.org/10.1038/ s41386-020-0775-z)

Publisher's note Springer Nature remains neutral with regard to jurisdictional claims in published maps and institutional affiliations.

\section{REFERENCES}

1. Gross C, Hen R. The developmental origins of anxiety. Nat Rev Neurosci. 2004:5:545-52

2. Whitaker-Azmitia PM, Druse M, Walker P, Lauder JM. Serotonin as a developmental signal. Behav Brain Res. 1996;73:19-29.

3. Gaspar P, Cases O, Maroteaux L. The developmental role of serotonin: news from mouse molecular genetics. Nat Rev Neurosci. 2003;4:1002-12.

4. Shah R, Courtiol E, Castellanos FX, Teixeira CM. Abnormal serotonin levels during perinatal development lead to behavioral deficits in adulthood. Front Behav Neurosci. 2018;12:114.

5. Oberlander TF, Papsdorf M, Brain UM, Misri S, Ross C, Grunau RE. Prenatal effects of selective serotonin reuptake inhibitor antidepressants, serotonin transporter promoter genotype (SLC6A4), and maternal mood on child behavior at 3 years of age. Arch Pediatr Adolesc Med. 2010;164:444-51.

6. Suri D, Teixeira CM, Cagliostro MKC, Mahadevia D, Ansorge MS. Monoaminesensitive developmental periods impacting adult emotional and cognitive behaviors. Neuropsychopharmacology. 2015;40:88-112.

7. Lira A, Zhou M, Castanon N, Ansorge MS, Gordon JA, Francis JH, et al. Altered depression-related behaviors and functional changes in the dorsal raphe nucleus of serotonin transporter-deficient mice. Biol Psychiatry. 2003;54:960-71.

8. Alexandre C, Popa D, Fabre V, Bouali S, Venault P, Lesch K-P, et al. Early life blockade of 5-hydroxytryptamine $1 \mathrm{~A}$ receptors normalizes sleep and depressionlike behavior in adult knock-out mice lacking the serotonin transporter. J Neurosci. 2006;26:5554-64.

9. Murphy DL, Lesch K-P. Targeting the murine serotonin transporter: insights into human neurobiology. Nat Rev Neurosci. 2008;9:85-96.

10. Vitalis T, Ansorge MS, Dayer AG. Serotonin homeostasis and serotonin receptors as actors of cortical construction: special attention to the 5-HT3A and 5-HT6 receptor subtypes. Front Cell Neurosci. 2013;7:93.

11. Teissier A, Soiza-Reilly M, Gaspar P. Refining the role of $5-\mathrm{HT}$ in postnatal development of brain circuits. Front Cell Neurosci. 2017;11:139.

12. Lebrand C, Cases $\mathrm{O}$, Wehrlé R, Blakely RD, Edwards RH, Gaspar P. Transient developmental expression of monoamine transporters in the rodent forebrain. J Comp Neurol. 1998:401:506-24.

13. Narboux-Nême N, Pavone LM, Avallone L, Zhuang X, Gaspar P. Serotonin transporter transgenic (SERTcre) mouse line reveals developmental targets of serotonin specific reuptake inhibitors (SSRIs). Neuropharmacology. 2008;55:994-1005.

14. Verney C, Lebrand C, Gaspar P. Changing distribution of monoaminergic markers in the developing human cerebral cortex with special emphasis on the serotonin transporter. Anat Rec. 2002;267:87-93.

15. Lebrand C, Gaspar P, Nicolas D, Hornung JP. Transitory uptake of serotonin in the developing sensory pathways of the common marmoset. J Comp Neurol. 2006;499:677-89.

16. Trowbridge S, Narboux-Nême N, Gaspar P. Genetic models of serotonin (5-HT) depletion: what do they tell us about the developmental role of 5-HT? Anat Rec. 2011;294:1615-23.

17. Amat J, Baratta MV, Paul E, Bland ST, Watkins LR, Maier SF. Medial prefrontal cortex determines how stressor controllability affects behavior and dorsal raphe nucleus. Nat Neurosci. 2005;8:365-71.

18. Robbins TW. Controlling stress: how the brain protects itself from depression. Nat Neurosci. 2005;8:261-2.

19. Warden MR, Selimbeyoglu A, Mirzabekov JJ, Lo M, Thompson KR, Kim S-Y, et al. A prefrontal cortex-brainstem neuronal projection that controls response to behavioural challenge. Nature. 2012;492:428-32.

20. Soiza-Reilly M, Meye FJ, Olusakin J, Telley L, Petit E, Chen X, et al. SSRIs target prefrontal to raphe circuits during development modulating synaptic connectivity and emotional behavior. Mol Psychiatry. 2019;24:726-45.

21. Kobe F, Guseva D, Jensen TP, Wirth A, Renner U, Hess D, et al. 5-HT7R/ G12 signaling regulates neuronal morphology and function in an age-dependent manner. J Neurosci. 2012;32:2915-30.

22. Speranza L, Chambery A, Di Domenico M, Crispino M, Severino V, Volpicelli F, et al. The serotonin receptor 7 promotes neurite outgrowth via ERK and Cdk5 signaling pathways. Neuropharmacology. 2013:67:155-67.

23. Speranza L, Labus J, Volpicelli F, Guseva D, Lacivita E, Leopoldo M, et al. Serotonin 5-HT7 receptor increases the density of dendritic spines and facilitates synaptogenesis in forebrain neurons. J Neurochem. 2017;141:647-61.
24. Volpicelli F, Speranza L, di Porzio U, Crispino M, Perrone-Capano C. The serotonin receptor 7 and the structural plasticity of brain circuits. Front Behav Neurosci. 2014;8:318.

25. Guscott M, Bristow LJ, Hadingham K, Rosahl TW, Beer MS, Stanton JA, et al. Genetic knockout and pharmacological blockade studies of the 5-HT7 receptor suggest therapeutic potential in depression. Neuropharmacology. 2005:48:492-502.

26. Hedlund PB, Huitron-Resendiz S, Henriksen SJ, Sutcliffe JG. 5-HT7 receptor inhibition and inactivation induce antidepressantlike behavior and sleep pattern. Biol Psychiatry. 2005;58:831-7.

27. Wesołowska A, Tatarczyńska E, Nikiforuk A, Chojnacka-Wójcik E. Enhancement of the anti-immobility action of antidepressants by a selective 5-HT7 receptor antagonist in the forced swimming test in mice. Eur J Pharm. 2007;555:43-47.

28. Bonaventure P, Kelly L, Aluisio L, Shelton J, Lord B, Galici R, et al. Selective blockade of 5-hydroxytryptamine (5-HT)7 receptors enhances 5-HT transmission, antidepressant-like behavior, and rapid eye movement sleep suppression induced by citalopram in rodents. J Pharm Exp Ther. 2007;321:690-8.

29. Wei YB, McCarthy M, Ren H, Carrillo-Roa T, Shekhtman T, DeModena A, et al. A functional variant in the serotonin receptor 7 gene (HTR7), rs7905446, is associated with good response to SSRIs in bipolar and unipolar depression. Mol Psychiatry. 2020;25:1312-22.

30. Beaudet G, Jozet-Alves C, Asselot R, Schumann-Bard P, Freret T, Boulouard M, et al. Deletion of the serotonin receptor type 7 disrupts the acquisition of allocentric but not egocentric navigation strategies in mice. Behav Brain Res. 2017;320:179-85.

31. Hagan JJ, Price GW, Jeffrey P, Deeks NJ, Stean T, Piper D, et al. Characterization of SB-269970-A, a selective 5-HT(7) receptor antagonist. $\mathrm{Br} J$ Pharm. 2000;130:539-48.

32. Viereckel T, Dumas S, Smith-Anttila CJA, Vlcek B, Bimpisidis Z, Lagerström MC, et al. Midbrain gene screening identifies a new mesoaccumbal glutamatergic pathway and a marker for dopamine cells neuroprotected in Parkinson's disease. Sci Rep. 2016;6:35203.

33. Kvachnina E, Liu G, Dityatev A, Renner U, Dumuis A, Richter DW, et al. 5-HT7 receptor is coupled to $\mathrm{G}$ alpha subunits of heterotrimeric $\mathrm{G} 12$-protein to regulate gene transcription and neuronal morphology. J Neurosci. 2005;25:7821-30.

34. Wirth A, Chen-Wacker C, Wu Y-W, Gorinski N, Filippov MA, Pandey G, et al. Dual lipidation of the brain-specific $\mathrm{Cdc42}$ isoform regulates its functional properties. Biochem J. 2013;456:311-22.

35. Teissier A, Le Magueresse C, Olusakin J, Andrade da Costa BLS, De Stasi AM, Bacci A, et al. Early-life stress impairs postnatal oligodendrogenesis and adult emotional behaviour through activity-dependent mechanisms. Mol Psychiatry. 2020;25:1159-74.

36. Soiza-Reilly M. Array tomography: a novel high-resolution immunofluorescence technique. In: Merighi A, Lossi L, editors. Immunocytochemistry and related techniques, vol. 101, New York, NY: Springer New York; 2015. p. 377-88.

37. Soiza-Reilly M, Anderson WB, Vaughan CW, Commons KG. Presynaptic gating of excitation in the dorsal raphe nucleus by GABA. Proc Natl Acad Sci USA. 2013;110:15800-5

38. Micheva KD, Smith SJ. Array tomography: a new tool for imaging the molecular architecture and ultrastructure of neural circuits. Neuron. 2007;55:25-36.

39. Peyron C, Petit JM, Rampon C, Jouvet M, Luppi PH. Forebrain afferents to the rat dorsal raphe nucleus demonstrated by retrograde and anterograde tracing methods. Neuroscience. 1998;82:443-68.

40. Gabbott PLA, Warner TA, Jays PRL, Salway P, Busby SJ. Prefrontal cortex in the rat: projections to subcortical autonomic, motor, and limbic centers. J Comp Neurol. 2005;492:145-77.

41. Weissbourd B, Ren J, DeLoach KE, Guenthner CJ, Miyamichi K, Luo L. Presynaptic partners of dorsal raphe serotonergic and GABAergic neurons. Neuron. 2014;83:645-62

42. Soiza-Reilly M, Commons KG. Unraveling the architecture of the dorsal raphe synaptic neuropil using high-resolution neuroanatomy. Front Neural Circuits. 2014;8:105.

43. Balcer OM, Seager MA, Gleason SD, Li X, Rasmussen K, Maxwell JK, et al. Evaluation of 5-HT7 receptor antagonism for the treatment of anxiety, depression, and schizophrenia through the use of receptor-deficient mice. Behav Brain Res. 2019;360:270-8.

44. Neumaier JF, Sexton TJ, Yracheta J, Diaz AM, Brownfield M. Localization of 5-HT(7) receptors in rat brain by immunocytochemistry, in situ hybridization, and agonist stimulated cFos expression. J Chem Neuroanat. 2001;21:63-73.

45. Vizuete ML, Venero JL, Traiffort E, Vargas C, Machado A, Cano J. Expression of 5HT7 receptor mRNA in rat brain during postnatal development. Neurosci Lett. 1997;227:53-56.

46. Béique J-C, Campbell B, Perring $P$, Hamblin MW, Walker $P$, Mladenovic $L$, et al. Serotonergic regulation of membrane potential in developing rat prefrontal cortex: coordinated expression of 5-hydroxytryptamine (5-HT)1A, 5-HT2A, and 5HT7 receptors. J Neurosci. 2004;24:4807-17. 
47. Andrade R. Serotonergic regulation of neuronal excitability in the prefrontal cortex. Neuropharmacology. 2011;61:382-6.

48. Naumenko VS, Popova NK, Lacivita E, Leopoldo M, Ponimaskin EG. Interplay between serotonin 5-HT1A and 5-HT7 receptors in depressive disorders. CNS Neurosci Ther. 2014;20:582-90.

49. Prasad S, Ponimaskin E, Zeug A. Serotonin receptor oligomerization regulates cAMP-based signaling. J Cell Sci. 2019;132:jcs230334. https://doi.org/10.1242/ jcs.230334.

50. Vertes RP. Differential projections of the infralimbic and prelimbic cortex in the rat. Synapse. 2004;51:32-58.

51. Meye FJ, Soiza-Reilly M, Smit T, Diana MA, Schwarz MK, Mameli M. Shifted pallidal co-release of GABA and glutamate in habenula drives cocaine withdrawal and relapse. Nat Neurosci. 2016;19:1019-24.

52. Trakhtenberg EF, Goldberg JL. The role of serotonin in axon and dendrite growth Int Rev Neurobiol. 2012;106:105-26.

53. Wirth A, Holst $K$, Ponimaskin E. How serotonin receptors regulate morphogenic signalling in neurons. Prog Neurobiol. 2017;151:35-56.

54. Ikeda M, Iwata N, Kitajima T, Suzuki T, Yamanouchi Y, Kinoshita Y, et al. Positive association of the serotonin 5-HT7 receptor gene with schizophrenia in a Japanese population. Neuropsychopharmacology. 2006;31:866-71.

55. Helsmoortel C, Swagemakers SMA, Vandeweyer G, Stubbs AP, Palli I, Mortier G, et al. Whole genome sequencing of a dizygotic twin suggests a role for the serotonin receptor HTR7 in autism spectrum disorder. Am J Med Genet B Neuropsychiatr Genet. 2016;171:1049-56.

56. Ansorge MS, Zhou M, Lira A, Hen R, Gingrich JA. Early-life blockade of the 5-HT transporter alters emotional behavior in adult mice. Science. 2004;306:879-81.

57. Popa D, Léna C, Alexandre C, Adrien J. Lasting syndrome of depression produced by reduction in serotonin uptake during postnatal development: evidence from sleep, stress, and behavior. J Neurosci. 2008;28:3546-54.

58. Sarkar A, Chachra P, Vaidya VA. Postnatal fluoxetine-evoked anxiety is prevented by concomitant $5-\mathrm{HT} 2 \mathrm{~A} / \mathrm{C}$ receptor blockade and mimicked by postnatal $5-\mathrm{HT} 2 \mathrm{~A}$ C receptor stimulation. Biol Psychiatry. 2014;76:858-68.

59. Golebiowska J, Hołuj M, Potasiewicz A, Piotrowska D, Kuziak A, Popik $P$, et al. Serotonin transporter deficiency alters socioemotional ultrasonic communication in rats. Sci Rep. 2019;9:20283.

60. Shelton J, Yun S, Losee Olson S, Turek F, Bonaventure P, Dvorak C, et al. Selective pharmacological blockade of the 5-HT7 receptor attenuates light and 8-OH-DPAT induced phase shifts of mouse circadian wheel running activity. Front Behav Neurosci. 2014;8:453.

61. Hajós M, Richards CD, Székely AD, Sharp T. An electrophysiological and neuroanatomical study of the medial prefrontal cortical projection to the midbrain raphe nuclei in the rat. Neuroscience. 1998;87:95-108.
62. Celada P, Puig MV, Casanovas JM, Guillazo G, Artigas F. Control of dorsal raphe serotonergic neurons by the medial prefrontal cortex: involvement of serotonin-1A, GABA(A), and glutamate receptors. J Neurosci. 2001;21: 9917-29.

63. Srejic LR, Hamani C, Hutchison WD. High-frequency stimulation of the medial prefrontal cortex decreases cellular firing in the dorsal raphe. Eur J Neurosci. 2015;41:1219-26.

64. Mayberg HS, Lozano AM, Voon V, McNeely HE, Seminowicz D, Hamani C, et al. Deep brain stimulation for treatment-resistant depression. Neuron. 2005;45:651-60.

65. Ferenczi EA, Zalocusky KA, Liston C, Grosenick L, Warden MR, Amatya D, et al Prefrontal cortical regulation of brainwide circuit dynamics and reward-related behavior. Science. 2016;351:aac9698.

66. Nikiforuk A, Hołuj M, Potasiewicz A, Popik P. Effects of the selective 5-HT7 receptor antagonist SB-269970 on premature responding in the five-choice serial reaction time test in rats. Behav Brain Res. 2015;289:149-56.

67. Grieb ZA, Ragan CM. The effects of perinatal SSRI exposure on anxious behavior and neurobiology in rodent and human offspring. Eur Neuropsychopharmacol. 2019;29:1169-84.

68. Abbas Al, Hedlund PB, Huang X-P, Tran TB, Meltzer HY, Roth BL. Amisulpride is a potent 5-HT7 antagonist: relevance for antidepressant actions in vivo. Psychopharmacology. 2009;205:119-28.

69. Okada M, Fukuyama K, Okubo R, Shiroyama T, Ueda Y. Lurasidone sub-chronically activates serotonergic transmission via desensitization of 5-HT1A and 5-HT7 receptors in dorsal raphe nucleus. Pharmaceuticals (Basel). 2019;12:149. https:// doi.org/10.3390/ph12040149.

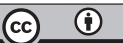

Open Access This article is licensed under a Creative Commons Attribution 4.0 International License, which permits use, sharing, adaptation, distribution and reproduction in any medium or format, as long as you give appropriate credit to the original author(s) and the source, provide a link to the Creative Commons license, and indicate if changes were made. The images or other third party material in this article are included in the article's Creative Commons license, unless indicated otherwise in a credit line to the material. If material is not included in the article's Creative Commons license and your intended use is not permitted by statutory regulation or exceeds the permitted use, you will need to obtain permission directly from the copyright holder. To view a copy of this license, visit http://creativecommons. org/licenses/by/4.0/.

(c) The Author(s) 2020 